\title{
Elementos para uma definição de justiça em educação ${ }^{1}$
}

Fábio D. Waltenberg

Professor do Departamento

de Economia da

Universidade Federal

Fluminense (UFF). Membro

do Núcleo de Estudos

em Educação (NEE)

do Centro de Estudos

sobre Desigualdade e

Desenvolvimento (Cede).

E-mail:

waltenberg@economia.uff.br
Resumo: Se o nível de educação de um indivíduo constitui vantagem (ou desvantagem) socioeconômica, e se é possível realocar recursos públicos a fim de alterar a distribuição de educação de uma população, então é preciso haver critérios para se avaliar o quão justas são diferentes distribuições de educação e para se definir o emprego de recursos que conduza a uma distribuição tão justa quanto possível. Este artigo oferece uma tentativa de sistematização da tarefa de se definir justiça em educação. Como quadro teórico para análises normativas, privilegiam-se refinamentos à abordagem convencional da economia do bem-estar, sobretudo aqueles proporcionados pelas teorias de funcionamentos e capacitações e de igualdade de oportunidades. Detalham-se implicações práticas da discussão no contexto brasileiro e apontam-se questões em aberto. Argumenta-se que refletir sobre justiça em educação é tarefa importante e plena de consequências, mas também uma empreitada elusiva.

Palavras-chave: Justiça em educação. Economia do bemestar. Funcionamentos e capacidades. Igualdade de oportunidades. Ideb.

\footnotetext{
Este artigo reflete o que foi apresentado na palestra "As distintas visões sobre princípios de distribuição de bens sociais e suas implicações para as políticas educacionais", durante o seminário "Justiça como equidade: princípios e práticas escolares", realizado nos dias 7 e 8 de fevereiro de 2013, organizado pelo Cenpec e pelo Governo do Estado do Ceará, sob responsabilidade de Vanda Ribeiro, a quem agradecemos o convite, tanto para a palestra como para esta publicação. Seu conteúdo baseia-se em uma série de pesquisas realizadas ao longo de vários anos e em diferentes locais, sobretudo na Université Catholique de Louvain, Bélgica, e na Universidade Federal Fluminense, que contaram com colaborações deliberadas ou involuntárias de inúmeros interlocutores, que não temos condições de listar nominalmente aqui, mas a quem somos gratos e de quem eximimos de qualquer responsabilidade. Também agradecemos a pareceristas e editores deste periódico pelas críticas e sugestões.
} 


\section{INTRODUÇÃO}

Por que deveríamos nos preocupar em definir justiça em educação? Há respostas variadas, não apenas em função da área do conhecimento de que provêm, como também em termos de sua natureza - mais conceitual ou mais concreta. Para economistas, uma motivação concreta decorre da constatação de que diferentes níveis de instrução e de certificação (diplomas) conferem vantagens ou desvantagens socioeconômicas aos indivíduos, seja, de modo mais evidente, no mercado de trabalho - diferenciais de renda durante a vida ativa, diferenciais de probabilidade de empregar-se e de duração de episódios de desemprego, etc. -, seja em instâncias não diretamente ligadas ao mercado de trabalho - diferenciais de renda na aposentadoria, de qualidade de condição de saúde, de longevidade, de possibilidade de exercício efetivo de liberdade; em suma, de qualidade de vida de um modo geral.

Se a quantidade ou a qualidade da educação "acumulada" por um indivíduo constituem uma vantagem ou uma desvantagem socioeconômica, e se consideramos que é possível realocar recursos públicos de forma a alterar a distribuição final de educação de uma população - por exemplo, destinar mais recursos públicos ao ensino superior e, assim, aumentar a proporção de graduados -, então torna-se necessário determinar critérios para se avaliar o quão justas são diferentes distribuições de educação (diagnóstico) e, a partir daí, definir o emprego de recursos que conduza a uma distribuição justa ou tão justa quanto possível (tratamento).

É relevante, portanto, definir-se justiça em educação a fim de se avaliar a distância entre algum ideal previamente estabelecido e a realidade; a fim de se comparar unidades tais como escolas, municípios, estados ou países em seu grau de respeito à justiça na área da educação; e a fim de orientar políticas públicas com impacto sobre educação pública e privada.

Do ponto de vista conceitual, contudo, ainda parece haver importantes lacunas e dificuldades na ciência econômica e em outras áreas do conhecimento quando se trata de prover uma definição de justiça em educação que, ao mesmo tempo, encontre-se isenta de críticas desestabilizadoras e que seja operacional para fins práticos, de "diagnóstico" e "tratamento", tais como definidos acima. Isso pode se dever ao fato de o tema só recentemente ter se tornado objeto de investigação - até há poucas décadas, muitas desigualdades eram vistas como naturais e, no que se refere à escola, o mero acesso parecia ser condição suficiente para se garantir justiça em educação².

Esta evolução de mentalidades está muito bem documentada na tese de Vanda Ribeiro (2012). 
Algumas dessas lacunas e dificuldades são destacadas neste artigo, entre as quais apontamos nesta introdução, a título de exemplificação e motivação, as seguintes:

- Qual é o locus adequado para o estabelecimento de critérios de justiça e verificação de seu cumprimento: a escola, o sistema escolar, a sociedade como um todo?

- É possível (e pertinente) combinar diferentes dimensões relevantes - por exemplo, conhecimento de matemática, despertar de espírito crítico, nível de bem-estar subjetivo do aluno - e agregá-las de alguma forma numa dimensão única que constituiria a métrica da justiça em educação?

- Se a meritocracia nos incomoda, por dissimular desigualdades prévias, até que ponto estamos dispostos a levar adiante a argumentação e eliminar toda e qualquer vantagem derivada do uso do critério de mérito acadêmico?

- Ainda que algumas desigualdades sejam claramente chocantes e absurdas, se não nos parece razoável classificar qualquer tipo de desigualdade em educação como injusta, onde traçar a fronteira entre o justo e o injusto?

Tendo em vista os desafios acima, que à primeira vista podem parecer desconectados ou independentes, o que se apresenta neste artigo é uma tentativa de organização ou sistematização da tarefa de se definir justiça em educação. Dado o caráter eminentemente normativo do objeto, é evidente que seria desastrada uma proposição de definição de justiça que aspirasse a ser consensual. No entanto, a impossibilidade de se alcançar tal definição "definitiva" não impede que se exponham argumentos favoráveis e contrários a determinadas visões normativas, nem que se desnudem limitações desta ou daquela escola de pensamento. O objetivo do artigo é, por assim dizer, "limpar o terreno de discussão", para que nele permaneçam as questões fundamentais, de modo organizado, facilitando o debate futuro.

0 artigo estrutura-se em quatro seções, além desta introdução. Na seção 1, apresentam-se as três escolhas fundamentais que precisam ser feitas quando se deseja realizar uma análise normativa - a esfera de justiça, a métrica e o método de agregação e síntese das informações obtidas de uma população -, e também se descreve em que medida a discussão sobre cada uma delas é aprofundada aqui ou remetida a outros estudos. A seção 2 destina-se a uma breve exposição dos pressupostos centrais de um ponto de partida para análises normativas, que é a abordagem convencional da economia 
do bem-estar. A seção 3 é central ao artigo por conter os refinamentos à análise econômica convencional que nos parecem ser os mais importantes, com ênfase na teoria de funcionamentos e capacitações, de Amartya Sen (1985, 1992), e na de igualdade de oportunidades, de John Roemer (1998). A seção 4 procura relacionar a discussão teórica das seções anteriores com 0 contexto brasileiro, apontando também algumas questões em aberto, tanto conceituais como práticas.

\section{ANÁLISE NORMATIVA: AS TRÊS ESCOLHAS FUNDAMENTAIS}

Por "análise normativa” denotamos exercícios de avaliação que envolvam juízo de valor. Pode ser feita por meio de uma descrição de estados sociais justos ou injustos de modo binário (ex.: "é injusto que algumas crianças não estejam na escola"; "é justo que todos tenham oportunidade de aprender"). Pode ser uma ordenação de estados sociais de acordo com seu grau de respeito à justiça (ex.: "o sistema de educação finlandês é mais justo que o brasileiro"; "é mais justa a educação no município de Indaiatuba do que no de Duque de (axias"). Pode se dar, por fim, através da observação de uma medida sintética (exemplo: 0 índice de desigualdade de Gini, alguma medida de pobreza, o Ideb).

Com base nas contribuições de uma série de economistas estudiosos de questões distributivas ${ }^{3}$, é possível afirmar que, para se efetuar uma análise de natureza normativa, é necessário realizar certas escolhas metodológicas fundamentais, por meio de respostas às seguintes questões:

1. Qual é o nível de análise relevante: micro, meso ou macrojustiça? No que se refere, especificamente, ao tema deste artigo, a justiça deveria ser avaliada e perseguida na escola, no sistema educativo ou na sociedade com um todo? De modo mais abrangente, a questão é: em que medida a educação pode ser considerada uma esfera de justiça adequada?

2. Se a educação for considerada uma esfera apropriada, a questão seguinte será: qual é a desigualdade, ou o conjunto de desigualdades, que importa? Qual é a métrica adequada?

3. Sendo a educação uma esfera apropriada, e tendo sido definida a métrica da justiça, pode-se indagar, por fim: que método deveria ser usado para sintetizar distribuições a fim de compará-las e julgá-las?

Por exemplo, Sen (1992), Cowell (1995), Fleurbaey (1995), Lambert (2001). 
A resposta à primeira questão não é trivial. Para ilustrar as dificuldades, imagine-se que, em decorrência de uma nova partilha de recursos federais, surjam montantes suplementares de verbas à disposição de determinado município, e que o prefeito possa aplicá-los à esfera educacional, contribuindo assim para minimizar uma preexistente injustiça educacional (de acordo com alguma concepção de justiça preestabelecida). Considere-se agora que, se os mesmos recursos fossem destinados à saúde, um maior grau de justiça em saúde (segundo alguma concepção de justiça) seria alcançado. Para completar a ilustração, admita-se que o uso de recursos em saúde contribua mais (ou menos, tanto faz) para o atingimento de justiça social (segundo alguma concepção de justiça). Nessas circunstâncias, que sentido haveria em se perseguir justiça nesta ou naquela esfera? 0 que importaria de fato não seria a justiça no nível da sociedade? Estando as escolhas de alocação de recursos sempre sujeitas a dilemas como este exemplificado acima, entre saúde e educação, valeria a pena refletir sobre detalhados critérios de justiça em educação ou em saúde, ou somente aqueles referentes à justiça social de modo abrangente teriam lugar?

Há contra-argumentos à proeminência da "macrojustiça” sobre níveis inferiores de justiça, como aqueles arrolados por Kolm (2002) ao advogar análises normativas em saúde, e sobretudo no trabalho de Walzer (1983), que defende análises segmentadas, esfera a esfera, com critérios possivelmente diferentes em cada uma delas, como a maneira adequada de se proceder, de modo a respeitar um princípio de não interferências entre esferas.

Não nos estenderemos aqui nessa discussão entre macrojustiça versus mesojustiça, assim como também não abordaremos o possível confronto entre a ideia de justiça no sistema educativo (nível meso) com a de justiça dentro de cada escola (nível micro). Mas cumpre mencionar que, mesmo essa escolha básica - geralmente desconsiderada, uma vez que muitos de nós tendemos a raciocinar de modo compartimentado, preocupados somente com a esfera que mais nos sensibiliza - está sujeita a controvérsias importantes

Posto que, de modo acertado ou equivocado, a legitimidade da educação como esfera de justiça relevante não costuma ser contestada, assumiremos daqui em diante - salvo menção em contrário - que a esfera educacional é um nível relevante de análise normativa, que pode ser expressa pela justiça avaliada no nível do sistema educativo (mesojustiça, portanto) de uma unidade geográfica ou política, e focaremos nosso olhar nas duas outras Destaque-se que tais controvérsias são discutidas de modo geral ou para a saúde pelos autores citados no parágrafo anterior, e no contexto da educação por Ribeiro (2012) e Waltenberg (2010). 
escolhas fundamentais - métrica e método de agregação - que variam muito de acordo com a teoria de justiça em questão, e cuja explicitação ajuda a compreender dilemas e desafios que afetam a tarefa a que se propõe este artigo.

De modo concreto, será preciso definir o atributo relevante - deve ser a satisfação dos alunos? Ou as notas em exames padronizados? Ou sua capacidade de pensar de modo autônomo? Ou os resultados no Ideb?

E, a seguir, dadas as distribuições de tal atributo em um ou mais grupos populacionais (ex.: ricos e pobres), caberá extrair alguma informação relevante para julgar o grau de justiça educativa na localidade em questão - a média geral ou para cada população? Alguma medida de dispersão intradistribuições? Ou interdistribuições? A proporção de indivíduos que não atingem resultados satisfatórios?

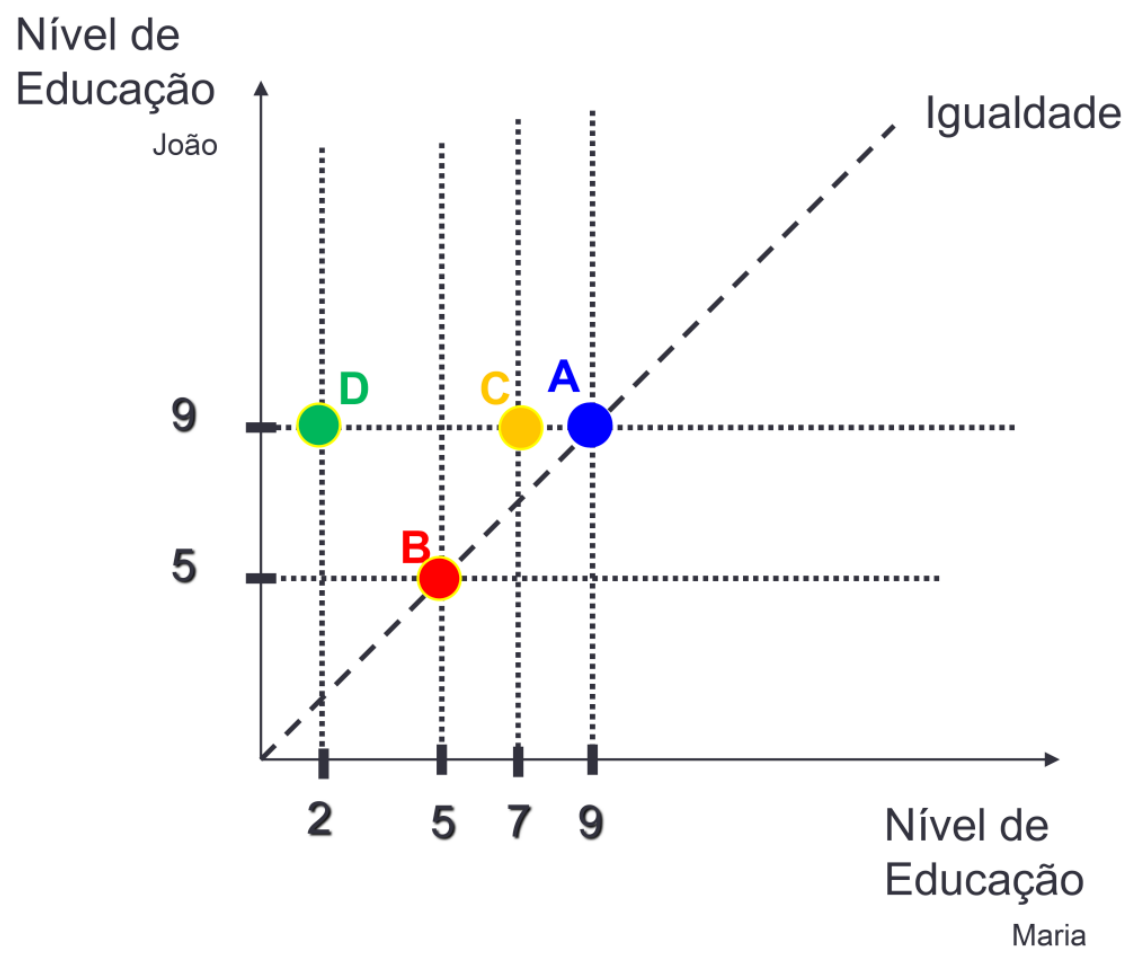

Figura $1 \mathrm{~A}$ - Distribuição de algum atributo entre dois grupos de determinada população - dois indivíduos 


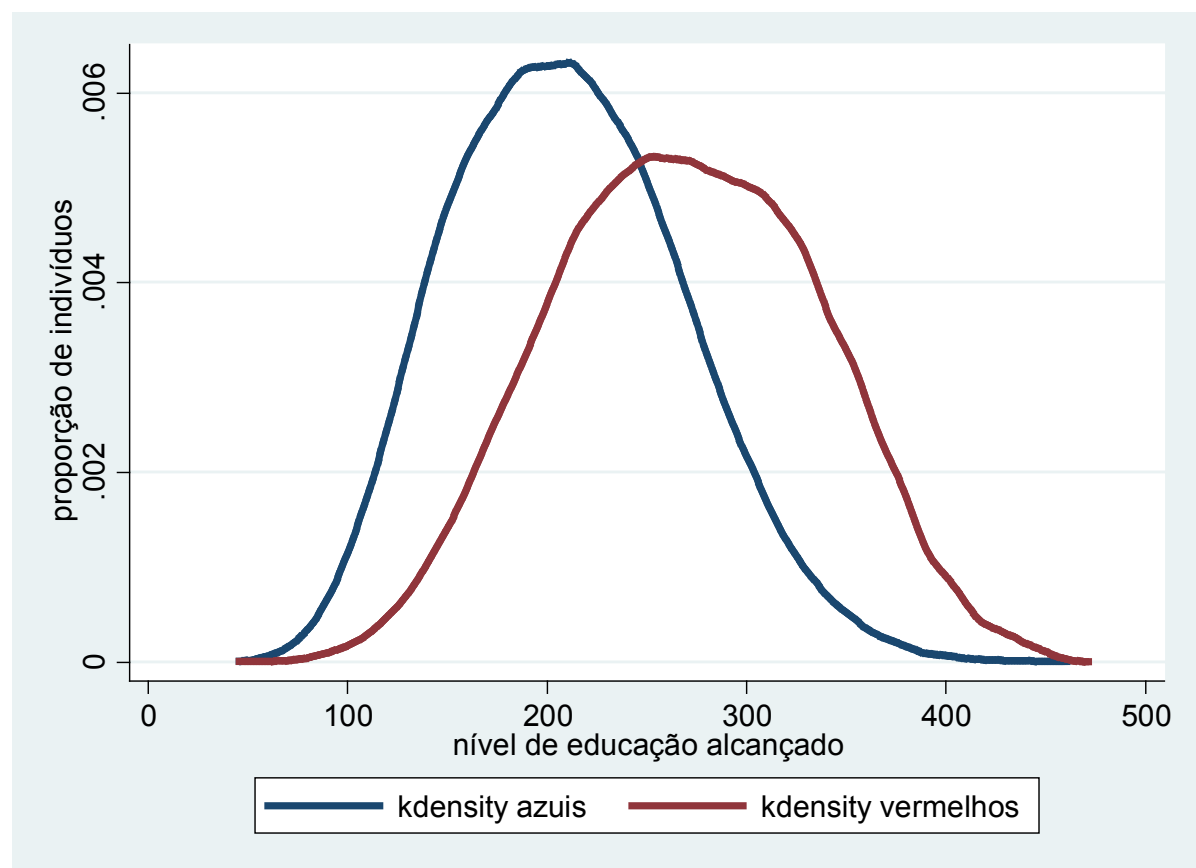

Figura 1B - Distribuição de algum atributo entre dois grupos de determinada população - inúmeros indivíduos pertencentes a dois grupos: azuis e vermelhos

A título de ilustração, ainda que por ora propositadamente vaga, a Figura 1 apresenta distribuições de um atributo específico (é irrelevante, por ora, que atributo seja) para dois indivíduos, João e Maria, na Figura 1A, e para dois grupos populacionais, vermelhos e azuis, na Figura $1 \mathrm{~B}^{5}$. Supondo que 0 atributo seja adequado (isto é, que a segunda escolha já tenha sido realizada), para julgar o quão justa em termos educativos é a unidade geográfica ou política representada em cada um dos painéis, será preciso interpretar as distribuições apresentadas, seja no Painel A (no qual cada um dos quatro pontos representa uma distribuição diferente), seja no Painel B (no qual cada uma das duas curvas representa uma distribuição diferente), e avaliar o que nos têm a dizer, o que constitui a terceira escolha. Para conferir mais conteúdo a essas escolhas, passemos à seção 2 .

Esta nota tem como objetivo facilitar a leitura dos gráficos. Na Figura $1 \mathrm{~A}$, os pontos $\mathrm{A}$ e $B$ representam situações de igualdade de níveis de educação entre João e Maria: 9 para ambos no primeiro caso, e 5 no segundo. Já os pontos C e $D$ indicam vantagem de João sobre Maria: 9 contra 7 no ponto C e 9 contra 2 no caso D. A Figura 1B apresenta distribuições de níveis de educação, cuja escala aparece no eixo horizontal (de 0 a 500), para duas populações com muitos indivíduos (azuis e vermelhos). 0 eixo vertical indica as proporções de indivíduos em cada nível de educação. Por exemplo, ao se observar a distribuição azul, nota-se que há uma forte concentração de indivíduos ao redor do nível 200 , enquanto a distribuição de vermelhos tem grande concentração um pouco mais à direita, já próxima aos 300 pontos. A amplitude das duas distribuições é parecida: ambas oscilam entre 50 e aproximadamente 480 . 


\section{PONTO DE PARTIDA: A VISÃO ECONÔMICA CONVENCIONAL}

Análises normativas não são privilégio desta ou daquela área de conhecimento, porém, a ciência econômica ocupa lugar de destaque, uma vez que tem dialogado com a filosofia política e disciplinas afins no debate conceitual sobre justiça distributiva - como evidenciado, por exemplo, pelas contribuições de autores como Sen (1985, 1992), Roemer (1998), Fleurbaey (1995, 1996) e tantos outros -, e também porque há, na ciência econômica, uma forte tradição quantitativa de desenvolvimento de instrumentos relevantes a diferentes teorias de justiça, como índices de desigualdade, pobreza e afins (veja-se Hoffman, 1998, ou Lambert, 2001).

O ponto de partida de análises normativas feitas por economistas costuma ser a economia do bem-estar convencional ${ }^{6}$, que se apoia em três pressupostos cruciais:

a) Foco em estados finais: resultados importam, processos não.

b) 0 que vale são preferências subjetivas: o bom não é predeterminado pelo pesquisador, por um especialista, pelo Estado ou por qualquer outra terceira parte, mas sim pelo próprio indivíduo, subjetivamente, consoante suas preferências.

c) Indivíduos autocentrados: as pessoas importam-se com seu próprio bemestar; isso não exclui a possibilidade de altruísmo, por exemplo - basta considerar que atos altruístas afetam positivamente o bem-estar do indivíduo que os pratica.

Além disso, em estudos quantitativos, é comum assumir critérios adicionais:

d) Uso de alguma variável proxy para refletir o nível de bem-estar (como renda ou consumo ou felicidade autodeclarada), uma vez que não existe uma medida perfeita de bem-estar subjetivo.

e) Definição de agente representativo: como não é possível observar de que modo cada indivíduo transforma insumos (ex.: renda) no atributo relevante (ex.: nível de bem-estar), fazem-se algumas suposições sobre esta função, como, por exemplo, a de que exista correlação positiva entre renda e bemestar, e a de que dois indivíduos com renda igual tenham, ceteris paribus, o mesmo nível de bem-estar.

6 Vejam-se, por exemplo, manuais clássicos de microeconomia, como Varian (1992) ou Mas-Colell et al. (1995), ou aplicações da economia do bem-estar ao estudo das políticas sociais, como em Barr (2012). 
Com base nesses critérios, é imediato vislumbrar a resposta da teoria econômica convencional à segunda escolha fundamental: a métrica relevante seria o bem-estar, determinado individual e subjetivamente. Fazendo-se referência à Figura 1, o que deveria ser medido nos eixos vertical e horizontal na Figura 1A, e no eixo horizontal na Figura 1B seriam os níveis de bem-estar dos indivíduos em questão, e não o que ali aparece ("nível de educação").

Portanto, com base na abordagem da economia do bem-estar convencional, o acesso ou não à escola, o tratamento recebido nas instituições escolares, o nível de instrução alcançado por um indivíduo, a qualidade da educação recebida (em todas as suas diferentes dimensões), o diploma obtido - enfim, os processos e resultados educativos mais comuns - não teriam nenhuma importância intrínseca. Somente importariam na medida em que fossem insumos para um maior bem-estar individual, qualquer que fosse o canal de "conversão" de educação em bem-estar, tais como nos seguintes exemplos: ser bem tratado na escola poderia impactar positivamente o bem-estar de um aluno; obter um diploma disputado o deixaria orgulhoso, aumentando seu bemestar; ter mais anos de estudo incrementaria sua renda, o que the permitiria comprar mais bens que lhe confeririam bem-estar mais elevado, etc.

Quanto ao método a ser usado para resumir distribuições, é possível definir, com base na economia do bem-estar convencional, uma infinidade de critérios, todos eles compreendidos entre dois extremos: o utilitarista e o “maximin” (forma reduzida da expressão “maximizar o mínimo"). Segundo o critério utilitarista, o bem-estar social é dado pela soma do bem-estar de todos os indivíduos, de modo que, na Figura $1 \mathrm{~A}$, o ordenamento normativo seria: $A, C, D, B$, isto é, a distribuição $A$ - que representa uma soma de 18 , visto que João tem 9 e Maria também - é preferida à distribuição C (soma: 16), que é preferida a $D$ (soma: 11), que é preferida a B (soma: 10). Já na Figura $1 B$, a distribuição vermelha representaria bem-estar mais elevado do que a azul, por estar a região central da distribuição daquela mais à direita que a desta, certamente com média mais elevada.

Segundo o critério do maximin, para se avaliar a qualidade de uma sociedade, não importa o bem-estar total, mas sim o bem-estar do indivíduo na pior situação. Na Figura 1 já comentada, em ambos os painéis, teríamos ordenamentos de distribuições diferentes com base no critério maximin em relação aos ordenamentos de utilitaristas. Na Figura $1 \mathrm{~A}$, o ordenamento seria A, C, B, D (contra A, C, D, B para utilitaristas). O ponto B seria preferido ao ponto $D$ segundo o maximin, mesmo que a soma do bem-estar em $B$ seja inferior àquela em $\mathrm{D}$. Na Figura $1 \mathrm{~B}$, o ordenamento indicaria igualdade entre 
as distribuições, uma vez que a base de ambas as distribuições é a mesma, ao redor de 50 (contra um ordenamento utilitarista que classificava vermelhos à frente de azuis).

Além dos critérios extremos, que só valorizam a soma (utilitarismo) ou que só atentam para o nível de quem tem menos (maximin), é possível definir uma ampla gama de critérios intermediários, que levem em conta tanto a soma quanto a dispersão entre indivíduos, com pesos definidos por um parâmetro denominado "grau de aversão à desigualdade" (ATKINSON; STIGLITZ, 1980).

A abordagem convencional do bem-estar foi alvo de fortes críticas (ex.: por Rawls, 1971, 1992; Sen, 1985, 1992, 2000), que podem ser sintetizadas em três grandes categorias, em ordem crescente de contundência e de consequências:

a) Críticas a um ou outro critério de agregação: por exemplo, críticas à insensibilidade do critério utilitarista à desigualdade, ao qual é, efetivamente, cego (ex.: a distribuição de um atributo entre três indivíduos dada por [10, 5, 0] é, aos olhos utilitaristas, tão boa quanto a distribuição $[5,5,5]$, uma vez que, em ambas, a soma é 15), ou ao foco exagerado no mais desfavorecido pelo critério maximin, ignorando a importância de uma média mais elevada (ex.: a distribuição [2, 3, 4] é, segundo o maximin, tão boa quanto [2, 10, 10]).

b) Críticas à métrica - deficiências técnicas: não é possível medir ou comparar o bem-estar individual de modo preciso. Ou será preciso recorrer a proxies, estando estas, contudo, sujeitas a contestação, ou então será preciso obter consenso em torno a uma política para que seja aceitável. Nesse último caso, a limitação é que grande parte das políticas envolvem ganhadores e perdedores (ex.: estabelecimento de política de cotas para acesso à universidades), e as análises normativas não dariam subsídios à tomada de muitas decisões se sempre dependêssemos de improváveis unanimidades.

c) Críticas à métrica - deficiências substantivas: a métrica do bem-estar subjetivo elimina a importância de qualquer informação objetiva. Não importa se um indivíduo encontra-se claramente em uma situação deplorável (ex.: é um miserável); desde que considere, subjetivamente, que está bem, ele terá desempenho elevado na métrica da economia do bem-estar convencional.

Com relação ao ponto (c) acima, vale lembrar que a métrica do bem-estar subjetivo também despreza a distribuição de qualquer indicador de educação, a menos que esta tenha algum valor instrumental como fonte de bem-estar. 
O conjunto de críticas aos diferentes critérios de agregação - ponto (a) acima - não é específico à abordagem convencional, muito pelo contrário. $\mathrm{Na}$ realidade, trata-se de discussões inevitáveis, pois traduzem visões normativas conflitivas, mesmo num contexto de consenso com relação ao escopo de análise e métrica. É inclusive mais interessante trabalhar-se com uma família de critérios de agregação, com parâmetros que reflitam diferentes preocupações normativas, do que fechar-se num único critério, certamente contestável. Contudo, as críticas à métrica são mais graves - de modo geral e para análises normativas em educação, em particular -, requerem mais atenção e serão abordadas na seção 3.

\section{REFINAMENTOS: QUESTIONAMENTOS DE PRESSUPOSTOS E UMA PROMISSORA} COMBINAÇÃO DE QUADROS TEÓRICOS

Um procedimento frutífero de evolução com relação à abordagem econômica convencional tem sido o de questionar os pressupostos cruciais (consequencialismo, subjetividade e individualismo) ou os adicionais (uso de proxy e homogeneidade), caminho que tem sido trilhado por muitos autores ao longo das últimas décadas.

John Rawls $(1971,1999)$ questiona todo o edifício teórico da economia do bem-estar, com fortes ataques aos pressupostos cruciais, sobretudo à subjetividade, uma vez que defende o uso de uma cesta (predefinida pelo próprio Rawls) de "bens primários" como métrica da qualidade de vida, em lugar de uma medida de bem-estar subjetiva. Especificamente no que tange à discussão de justiça em educação e às três escolhas fundamentais de análises normativas, Rawls não aprovaria educação como esfera de justiça autônoma (pois sua preocupação situa-se no nível da macrojustiça) e discordaria de uma métrica que fosse baseada em algum indicador de processo ou produto educacional (pois sua unidade de medida são bens primários, que não incluem educação). Como método de agregação, privilegia o maximin não na dimensão de bem-estar, nem de educação, mas sim do conjunto de bens primários. No que se refere à Figura 1, os eixos deveriam indicar bens primários, ou seriam irrelevantes, e o ordenamento das distribuições seria igual ao já explicado quando da discussão do critério do maximin. Conclui-se que Rawls não lança muitas luzes à questão que nos ocupa neste artigo.

Em que pese a influente contribuição de Rawls às discussões de natureza normativa de modo geral, para o caso específico de justiça em educação, os trabalhos de Amartya Sen $(1982,1992)$ e de John Roemer (1998) são 
mais significativos. Sen louva os esforços de Rawls para desbancar a predominância da economia do bem-estar, porém também o critica, pois, ao recorrer a uma cesta de bens primários, se, por um lado, os problemas decorrentes da subjetividade de fato se esvaem, por outro lado, criamse novas deficiências decorrentes do uso de uma métrica objetiva: ora, as preferências individuais deveriam ser ignoradas? O que importa para todo e qualquer indivíduo é sintetizado pela cesta de bens primários definida por um filósofo em seu gabinete na Universidade Harvard? É plausível supor que dois indivíduos que detenham a mesma cesta de bens primários necessariamente terão a mesma qualidade de vida, ou seria recomendável levar-se em conta a heterogeneidade interpessoal?

Com respeito à discussão de justiça em educação e às três escolhas fundamentais de análises normativas, Sen aceitaria a educação como uma esfera de justiça autônoma desde que isso fosse decidido democraticamente, pois não crê que algum pesquisador tenha como distinguir, de antemão, as esferas de justiça relevantes das não relevantes. Quanto à métrica, prega o foco em "funcionamentos", que são resultados concretos - e não apenas insumos para que resultados sejam alcançados, como são os bens primários, nem resultados subjetivos como é o bem-estar - e em "capacitações”, que são oportunidades reais para se alcançar resultados relevantes, ou seja, uma medida da liberdade real do indivíduo.

Assim, em educação, o que importaria não seriam diretamente os insumos recebidos por um aluno, nem o valor subjetivo atribuído pela pessoa à educação alcançada, mas sim um conjunto de resultados democraticamente apontados como relevantes na sociedade em questão (ex.: possuir determinado diploma) e a ampliação da possibilidade de alcançar outros resultados relevantes, em educação ou em outras áreas (ex.: diploma obtido que abra portas para etapa subsequente de educação, ou educação como fomentadora de melhor condição de saúde). Sen não se arrisca a defender um método de agregação específico, pois, também nesse aspecto, considera que se trata de decisão a ser tomada democraticamente em cada localidade. Mas é possível depreender de sua análise que, se a educação é, simultaneamente, um funcionamento e uma capacitação relevantes, seria recomendável assegurar que todos os cidadãos alcançassem ao menos certo patamar básico de educação. Na Figura 1, seria razoável determinar um nível mínimo de educação, e criar indicador que identificasse escola ou unidade política que não garantisse que todos o alcançassem. 
Observada uma desigualdade entre indivíduos em determinada dimensão (ex.: acesso à escola para uns, mas não para outros), John Roemer (1998)7, por sua vez, propõe que se distinga em que medida tal desigualdade deve-se a circunstâncias favoráveis ou desfavoráveis (ex.: pais ricos ou pobres) e em que medida se deve a diferenças em termos de exercício da responsabilidade individual (ex.: maior ou menor dedicação aos estudos). Posto que seria inadequado comparar níveis de exercício de responsabilidade individual entre indivíduos sujeitos a diferentes circunstâncias, Roemer propõe que se divida a população em grupos, chamados de “tipos”. Cada tipo é composto por indivíduos iguais (ou parecidos) no que tange às circunstâncias. Por serem iguais ou parecidos, os indivíduos de cada tipo que alcançassem melhores resultados seriam legítimos beneficiários das vantagens sociais deles decorrentes. Desigualdades intertipos seriam consideradas ilegítimas, enquanto aquelas intratipos seriam toleráveis. Em suma, o que Roemer propõe é uma meritocracia condicional ao tipo.

Duas posições normativas constituem casos-limite dentro da teoria de igualdade de oportunidade: (i) "meritocática pura” e (ii) "antimeritocrática pura”. Nos termos de Roemer, aquela seria cega às circunstâncias, considerando que qualquer desigualdade deva ser vista como fruto de diferencial de esforço ou mérito, e, portanto, legítima, de sorte que todos os indivíduos deveriam pertencer a um único tipo $(T=1)$. A visão oposta reflete a consideração de que qualquer desigualdade deva ser vista inteiramente como fruto de circunstâncias limitantes - especialmente em educação, por se tratar de crianças, adolescentes e jovens, cuja capacidade de exercício do livre-arbítrio ainda não estaria plenamente desenvolvida. A implicação seria considerar que cada tipo seria povoado por apenas um indivíduo, definido por uma combinação única de circunstâncias ( $T=n$, onde $n$ representa o número de indivíduos na população).

Para fixar ideias, reflitamos sobre qual seria a opinião dos partidários das posições (i) e (ii) acima sobre uma política de cotas raciais para acesso à universidade. Os primeiros tenderiam a repudiar as cotas por ferirem a meritocracia e defenderiam um vestibular tradicional. Os antimeritocráticos poderiam repudiar as cotas por levarem em consideração um conjunto restrito de circunstâncias (cor/raça), quando, na realidade, muitas outras circunstâncias seriam restringentes (pobreza, condições familiares, local de moradia etc.); no limite, caso haja oferta insuficiente de vagas, recomendariam sorteio para atribuição de direito à matrícula.

Esta exposição da teoria de John Roemer (1998) baseia-se em Mendes Jr. e Waltenberg (2013). 
Talvez mais interessante do que as extremas sejam posições intermediárias da ideia de meritocracia condicional de Roemer, com número de tipos tal que $1<T<n$. Se os tipos fossem definidos somente em termos de gênero $(T=2)$, e supondo uma sociedade composta apenas por Maria e João, como no Painel A da Figura 1, Roemer consideraria que os pontos A e B refletem situações de igualdade de oportunidades, uma vez que ambos representam igualdade intertipos (isto é, entre gêneros); já os pontos C e D traduziriam desigualdade intertipos (intoleráveis), com a distribuição D ainda mais distante da igualdade de oportunidades que a C. Porém, caso os tipos fossem definidos em função de riqueza, e se João e Maria tivessem renda familiar idêntica, as distribuições representadas pelos pontos A, B, C e D na Figura 1A seriam todas desigualdades intratipos (toleráveis), sendo, portanto, indiferenciáveis do ponto de vista normativo.

Roemer introduz seu quadro de análise, mas não define parâmetros específicos de políticas. Em particular, não traz respostas prontas a questões tais como: (a) Quais vantagens sociais devem ser alvo de escrutínio e de eventuais correções?; (b) Qual definição de tipos é a mais adequada, isto é, quais são de fato as circunstâncias limitantes relevantes? (c) Deve-se equalizar totalmente as oportunidades, ou outros critérios devem ser levados em conta? Por exemplo, num eventual dilema entre eficiência e equidade, que peso atribuir a cada um? A discussão sobre tais parâmetros - inescapavelmente normativa - caberia a cada sociedade. A falta de definições tem sido interpretada ora como virtude (flexibilidade), ora como deficiência (imprecisão) da teoria de Roemer.

Fleurbaey (1995), com base em propostas anteriores de igualdade de oportunidade de Roemer e outros autores, propusera um compromisso interessante: enquanto seria tarefa da sociedade assegurar que todos alcançassem realizações fundamentais básicas iguais, incluindo algum nível de educação a definir, caberia aos indivíduos irem além, ou não, em função de suas preferências, potencialidades, esforços. Em termos roemerianos: até certa idade ou série, adotar-se-ia postura puramente antimeritocrática; a partir de então, encampar-se-ia a meritocracia. Ao observar o caso francês, o autor propõe a meta social de que o diploma do secundário fosse obtido por todos os cidadãos. Nesse sentido, por caminho diverso, aproxima-se das conclusões de uma abordagem baseada na teoria de funcionamentos e capacitações $^{8}$.

8 No apêndice, encontra-se quadro-resumo que sintetiza as respostas dadas pelos diferentes marcos teóricos abordados nas seções 2 e 3 às três questões fundamentais: (a) qual é o nível de análise adequado?, (b) qual é a métrica apropriada?, (c) qual é o método de agregação ou de síntese? 
Em suma, a teoria de igualdade de oportunidades difere da economia convencional ao não restringir o equalisandum a resultados subjetivos ou as proxies destes (em contraste com os pressupostos $b$ e $d$ ), ao considerar estados finais, porém condicionados a características de demais indivíduos (em contraste com os pressupostos $a, c$ e $e$ ). No que se refere às três escolhas fundamentais, a teoria é suficientemente flexível para se prestar a análises normativas nos níveis micro, meso ou macro; a métrica é a que for desejada (e devidamente justificada) pelo pesquisador; o método de agregação requer a quantificação da desigualdade total e sua decomposição entre desigualdade intratipos (tolerável) e desigualdade intertipos (injusta) - quantificações têm sido realizadas em profusão em anos recentes, conforme documentado nas resenhas de Pignataro (2012) e Ramos e Van de Gaer (2012), seja em termos de oportunidade de acesso a diferentes níveis de ensino (PAES DE BARROS et al., 2009; VEGA et al., 2010), seja em termos de oportunidade de resultados em provas padronizadas (CHECCI; PERAGINE, 2005; FERREIRA; GIGNOUX, 2011; GAMBOA; WALTENBERG, 2012).

No cômputo geral, portanto, a teoria de igualdade de oportunidades revela-se bastante adequada à análise normativa na esfera da educação, e proporciona flexibilidade suficiente para acomodar diferentes níveis de análise (micro, meso ou macro), diferentes métricas (acesso, desempenho, multidimensionais) e diferentes posições normativas (variando, parametricamente, entre uma aversão nula à meritocracia e um repúdio total a ela). Ao combiná-la com a teoria de funcionamentos e capacitações, que delega in fine às instâncias democráticas a deliberação sobre as especificidades dessas três escolhas, obtém-se uma boa diretriz para análises normativas na área de educação.

\section{RELEVÂNCIA DA DISCUSSÃO PARA O CONTEXTO BRASILEIRO E QUESTÕES EM ABERTO}

A fórmula de um indicador sintético de "qualidade da educação" como o Índice de Desenvolvimento da Educação Básica (Ideb) leva em conta, com o mesmo peso, duas dimensões - aprendizado e fluxo - na caracterização da qualidade de uma escola ou rede de ensino (municipal, estadual, federal ou privada), porém, embora ambas as que compõem o Ideb sejam de fato importantes, não são únicas. Se houver, por exemplo, duas escolas (ou redes) com o mesmo Ideb, mas uma dessas entidades apresentar alto grau de desigualdade de oportunidades educativas, ela não deveria ser penalizada?

Tanto os índices de igualdade de oportunidade teóricos, mencionados na 
seção 3, quanto os indicadores concretos, como o ldeb, na realidade nada mais fazem do que definir dimensões que refletem aquilo que se determina como desejável que uma escola, ou rede ou país procure alcançar, e retiram valor de tudo o que não esteja expresso na fórmula em questão. Ou seja, têm muito em comum. Em assim sendo, com base no que foi exposto neste artigo, certamente faria sentido identificar de alguma forma uma escola (ou rede) com alto grau de desigualdade de oportunidades educativas - isto é, tal dimensão deveria ser incorporada a um eventual Ideb aprimorado.

A leitura do último parágrafo da seção 3 - em que se recomenda uma combinação dos quadros teóricos de Sen e Roemer para a realização de análises normativas em educação - e dos dois primeiros desta seção pode propiciar uma confortável sensação de que não apenas teríamos resolvido o problema teórico que nos ocupa, como também teríamos encontrado uma maneira de levá-lo em conta, de forma concreta, ao sugerir um aperfeiçoamento do principal indicador usado como proxy de qualidade da educação brasileira. Tal sensação de conforto, no entanto, é efêmera, pois os questionamentos que se abrem a partir da convergência da literatura de análise normativa - em suas vertentes conceitual e instrumental - com a de avaliação educacional não se limitam à sugestão de incorporação de alguma medida de dispersão condicional (a partir de Roemer) a indicadores como o Ideb, os quais, por sua vez, reafirmam a educação como esfera de justiça (a partir de Sen). Muitos outros questionamentos despontam simultaneamente, constituindo desafios para reflexões e esforços de pesquisa futuros, tais como os listados a seguir:

- Desempenho em provas de português e matemática traduzem "qualidade da educação"? Constituem boa métrica de "justiça em educação"? Seria necessário incorporar outras disciplinas para evitar estreitamento de objetivos (e de currículos)? Incorporar disciplinas bastaria para se construir um bom indicador? Quais disciplinas? Como traçar a fronteira entre que é essencial e o que não é?

- Não é temerário atribuir, numa medida de “qualidade da educação”, um peso de $50 \%$ a testes padronizados, de resto tão facilmente criticáveis em tantos aspectos? Não é um peso elevado demais?

- É possível (e pertinente) combinar diferentes dimensões relevantes ex.: conhecimento de matemática, despertar de espírito crítico, nível de bem-estar subjetivo do aluno - e agregá-las de alguma forma numa dimensão única que constituiria a métrica da justiça em educação (ou de "qualidade da educação")? Ganhamos mais do que perdemos ao 
agregar várias dimensões?

- Se transmitir conhecimento aos alunos é uma das tarefas que se espera da escola, faria sentido que o Ideb relevante para fins avaliativos fosse uma medida de "valor agregado" e não uma mera medida de nível observado em determinado momento? 0 que se perde e o que se ganha com isso, uma vez que medidas de valor agregado também estão sujeitas a erros de medida, choques aleatórios exógenos e outras fontes de imprecisão?

- Parece razoável incluir alguma medida de "pobreza educacional" (desempenho inferior a certo patamar) no Ideb? Como definir a "linha de pobreza educacional"?

- Como propor medidas de qualidade de educação (ou métrica de justiça educacional) que não incentivem seleção de potenciais bons alunos no momento da matrícula ou no momento de aplicação de provas padronizadas, evitando temores de seleção discriminatória como aqueles expressos por Ooghe e Schokkaert (2013)?

Talvez seja desnecessário dizer que não temos respostas a todas as questões acima. Também deve estar claro que a ausência de tais respostas deita por terra a provisória sensação de que a definição de justiça em educação seria tarefa concluída. Contudo, o mais importante é que se compreenda que essas novas questões dialogam com os cinco pressupostos da economia do bem-estar convencional, com as críticas a eles e com as três escolhas fundamentais de análises normativas, às quais fizemos alusão ao longo do texto. Se essa compreensão ocorrer, o objetivo do artigo terá sido alcançado, ainda que a sensação final seja a de que refletir sobre justiça em educação é uma empreitada cheia de percalços, que não foi, nem será, resolvida ou concluída. 


\section{Towards a definition of justice in education}

Abstract: If an individual's education level provides socioeconomic advantages (or disadvantages), and if it is possible to reallocate resources in such a way as to alter the distribution of education in a given population, then it is necessary to devise criteria to evaluate how just are different distributions of education and to define how resources could be assigned in order to conduct to a as-just-as-possible distribution. This paper attempts at systematizing the task of defining justice in education. As for theoretical frameworks to undertake normative analyses, refinements to standard welfare economics are emphasized, especially those offered by the theories of functionings and capabilities, and equality of opportunities. Practical implications for the Brazilian context are discussed, and open questions are unveiled. We argue that reflecting about justice in education is an important task, with plenty of consequences, but also an elusive endeavor.

Keywords: Justice in education. Welfare economics. Functionnings and capabilities. Equality of opportunity. Ideb. 


\section{REFERÊNCIAS}

ATKINSON, A. B.; STIGLITZ, J. E. Lectures on public economics. New York: McGraw Hill, 1980.

BARR, N. Economics of the welfare state. 5th ed. Oxford: Oxford University Press, 2012.

CHECCHI, D.; PERAGINE, V. Regional disparities and inequality of opportunity: the case of Italy. IZA Discussion Papers 1874, Institute for the Study of Labor (IZA), 2005.

COWELL, F. A. Measuring inequality. 2nd ed. Harvester, Wheastsheaf: Prentice Hall, 1995.

FERREIRA, F.; GIGNOUX, J. The measurement of educational inequality: achievement and opportunity. Working Papers 240, Ecineq, Society for the Study of Economic Inequality, 2011.

FLEURBAEY, M. Equal opportunity or equal social outcome? Economics and Philosophy, v. 11, p. 25-55, 1995.

. Théories économiques de la justice. Paris: Economica, 1996.

GAMBOA, L. F.; ALTENBERG, F. D. Inequality of opportunity in educational achievement in Latin America: evidence from Pisa 2006-2009. Economics of Education Review, v. 31, n. 5, p. 694-708, October 2012.

HOFFMAN, R. Distribuição de renda e pobreza. São Paulo: Edusp, 1998, caps. 4 e 5 .

KOLM, S. C. On health and justice. Paris: Institute for Advanced Studies in the Social Sciences, 2002. (mimeo).

LAMBER, P. The distribution and redistribution of income. 3rd edition. Manchester: Manchester University Press, 2001.

LEVIN, H. M. The necessary and sufficient conditions for achieving educational equity. In: BERNE, R.; PICUS, L. Outcome equity in education. Thousand Oaks, Ca.: Corwin Press, 1994.

MAGUAIN, D. Les théories de la justice distributive post-rawlsiennes: une revue de la littérature. Révue Economique, v. 53, n. 2, p. 165-199, 2002. 
MAS-COLELL, A.; WHINSTON, M. D.; GREEN, G.R. Microeconomic theory. Oxford: Oxford University Press, 1995.

MENDES JR., A. A. F.; WALTENBERG, F. D. Uma política de cotas não raciais é capaz de proporcionar a admissão de muitos negros na universidade? Simulações para a Uerj. Rio de Janeiro: Universidade Federal Fluminense, 2013. (mimeo).

MEURET, D. La justice du système éducatif. Paris: De Boeck Université, 1999.

OOGHE, E.; SCHOKKAERT, E. School accountability: can we reward schools and avoid pupil selection? IZA Discussion Paper 7420, 2013.

PAES DE BARROS, R.; FERREIRA, F.; MOLINAS, J.; SAAVEDRA, J. Measuring inequality of opportunities in Latin America and the Caribbean. Washington, D.C.: World Bank, 2009.

PIGNATARO, G. Equality of opportunity: policy and measurement paradigms. Journal of Economic Surveys, v. 26, n. 5, p. 800-834, 2012.

RAMOS, X.; VAN DE GAER, D. Empirical approaches to inequality of opportunity: principles, measures, and evidence. Working Papers 259, Ecineq, Society for the Study of Economic Inequality, 2012.

RAWLS, J. A theory of justice. Cambridge, MA: Harvard University Press, 1971. . A theory of justice. Revised edition. Oxford: Oxford University Press, 1999.

RIBEIRO, V. M. Justiça na escola e regulação institucional de redes de ensino do Estado de São Paulo. 2012. 455f. Tese (Doutorado em Educação) - Faculdade de Educação da Universidade de São Paulo, São Paulo, 2012.

ROEMER, J. Equality of opportunity. Cambridge, MA: Harvard University Press, 1998.

SEN, A. K. Commodities and capabilities. North-Holland: Elsevier, 1985. . Inequality re-examined. Oxford: Clarendon Press, 1992.

Social justice and the distribution of income. In: ATKINSON, A. B.; BOURGUIGNON, F. (Eds). Handbook of income distribution. v. 1. North-Holland: Elsevier, 2000.

VARIAN, H. Microeconomic theory. 3rd ed. New York: Norton, 1992. 
VEGA, J. R. M.; PAES DE BARROS, R. P. de; SAAVEDRA, J.; GUIBALE, M. Do our children have a chance? The 2010 human opportunity report for Latin America and the Caribbean. Washington, D.C.: World Bank, 2010.

WALTENBERG, F. D. Essential educational achievements as the currency of educational justice. Cuadernos de Economía, Bogotá, v. 29, p. 103-126, 2010.

WALZER, M. Spheres of justice. New York: Basic Books, 1983.

RECEBIDO: Agosto de 2013.

APROVADO: Outubro de 2013. 
Apêndice: quadro-resumo das diferentes visões discutidas no artigo.

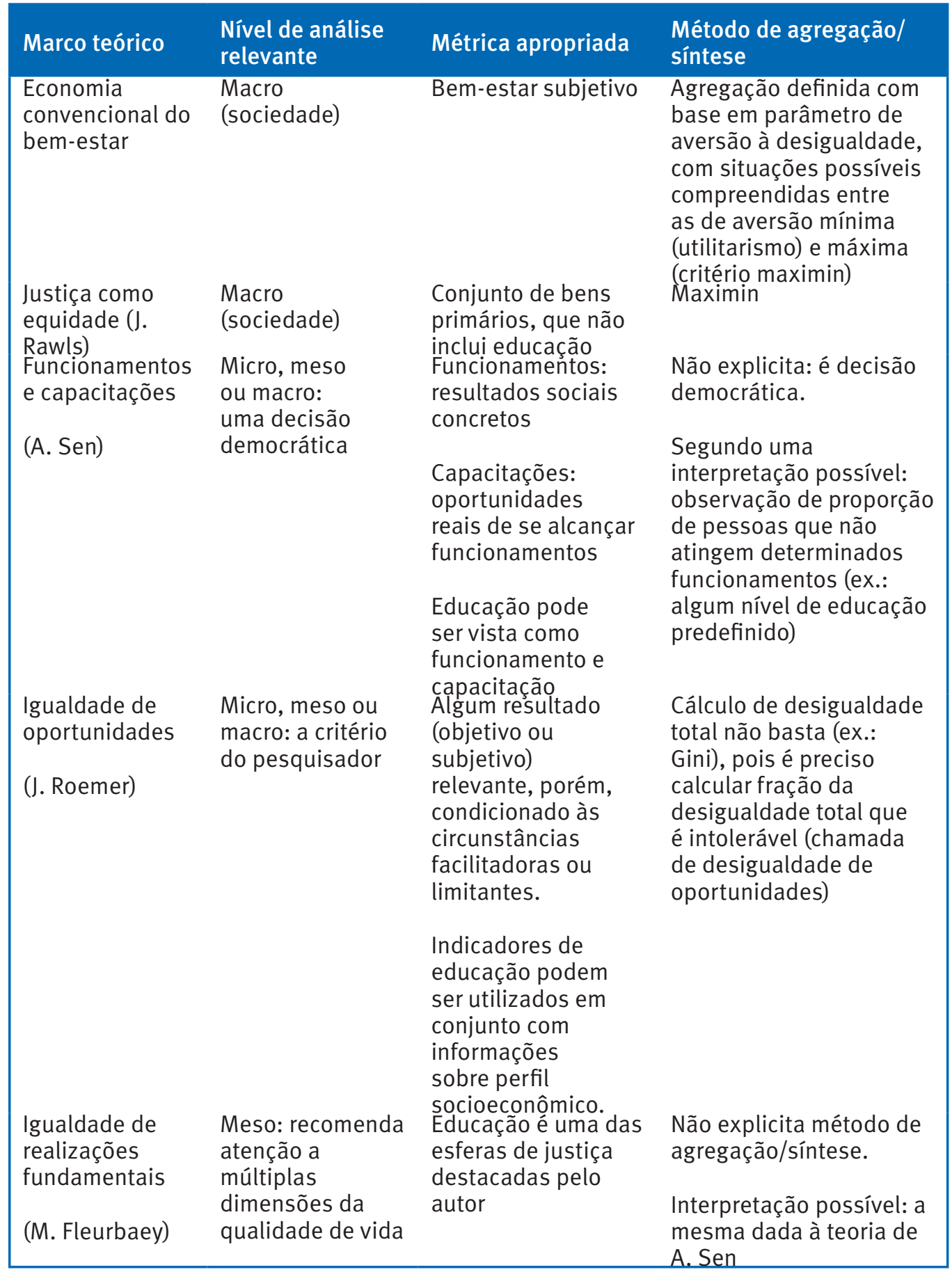

